\title{
Africa on the Verge of a Linguistic Genocide: The Need for Action
}

\author{
Eucharia Okwudilichukwu Ugwu, \\ Department of Arts and Social Sciences Education, \\ University Of Ibadan, Nigeria
}

Doi:10.19044/esj.2019.v15n23p57～URL:http://dx.doi.org/10.19044/esj.2019.v15n23p57

\begin{abstract}
Linguistic diversity is one of the rich endowments of the African continent. Language has a lot of potential benefits to the world at large and, most especially, to the people who speak it. However, in the present globalised world, language endangerment has become a stark reality as many world languages threaten the survival of the weaker ones spoken by the numerous indigenous people. In this mere linguistic warfare which the world has been plunged into, languages that are well-developed and have more speakers have greater chances of surviving. Due to the large number of languages in Africa, it may appear, on the periphery, as though these languages are safe. However, available statistics shows that the wave of language endangerment is already sweeping through the continent, as a result of which many African languages have gone into extinction and many are heading towards the same fate, unless a drastic action is taken. No part of Africa is safe and almost all African languages are threatened to some degree. This paper exposes the conditions of African indigenous languages and the need for actions to be taken to avert linguistic genocide in the continent.
\end{abstract}

Keywords: African indigenous languages, Language endangerment in Africa, Linguistic genocide in Africa, Linguistic diversity in Africa, Language extinction in Africa

\section{Introduction}

One of the extraordinary resources of the African continent is linguistic pluralism. Apart from Asia which has about 33\% of all the languages spoken around the world, Africa is the second largest linguistically rich continent, being a home to up to $30 \%$ of the existing languages (Simons \& Charles, 2018). Most of the African languages are concentrated in the Sub-Saharan region which alone has about one-third of the world's languages (Moseley, 2010 , p. 20). In many African countries, a complete documentation of the number of indigenous languages present has not been achieved, largely 
because most of them exist exclusively in oral forms, spoken by the numerous rural and minority groups.

Languages are rich resource of the society that need not be taken for granted. Every language spoken in Africa, and in the world at large, was handed over by the previous generations, and the present generation has the duty to sustain and preserve them for the upcoming generations. Unfortunately, today, the survival of many African languages is at stake.

UNESCO (2003) estimates that about $90 \%$ of the world's languages may be replaced by the few dominant ones by the end of the 21 st century. Also, the United Nations (2016) reiterates that "in the absence of immediate and concerted action, the world is entering a major linguistic and cultural extinction event, on a scale with major extinction events of the past in which a majority of the world's species have become extinct" (p. 13). Languages that have written forms have greater chances of surviving in the present globalized world. However, most of the African languages remain unwritten, making them fragile and open to the waves of linguistic extinction. Moseley (2010) believes that more than a hundred African languages "exist only by name" and were therefore omitted from its lists of endangered languages, and that for the remnants, up to $10 \%$ of them, "especially those spoken by the minority groups may actually disappear within the next hundred years" (p. 20). The ones that "exist only by name" might have gone into extinction. This is worrisome. So far, only six out of the 7,480 identified languages in the world are classified as "international", that is "widely used between nations in trade, knowledge exchange, and international policy" (Simons \& Lewis, 2013, p. 22). These "big six languages" definitely pose a threat to the other world's languages as socio-economic and political ties or relationships among countries continue to increase.

Once lost, a language can hardly ever be revitalised. The peculiar problem in Africa is that sometimes, both the languages spoken by the local communities and their speakers are at a high risk of disappearing. In that case, the issue of language revitalisation becomes even more out of the question. Moseley (2010) observes that "in sub-Saharan Africa, not only languages but often the speakers themselves are threatened by external forces such as military, economic, religious, cultural or educational pressures" (p. 21). If the poor rural speakers cannot save themselves from the plagues of poverty and marginalisation, how can they salvage their languages from extinction?

In an international conference on African languages organized by the writers and scholars from the different African regions in 2001, the delegates had "noted with pride that despite all the odds" against the African languages, these, languages "as vehicles of communication and knowledge survive and have a written continuity of thousands of years" (The Asmara Declaration, 2000 , p. 1). The question is, how many of the languages have actually 
survived, and how many are going to survive in the near future? The conference took place 19 years ago. In Nigeria for example, there has not been serious effort to promote the indigenous languages in the public arena, namely, education, politics and the media, three key sectors that could greatly increase language vitality. The educational sector has continued to endorse the use of English rather than the indigenous languages. consequently, there is a general preference for education delivered solely in English, and many schools, even at the pre-primary and primary school levels would not welcome the use of the indigenous languages for instructional purposes (Ezenwa-Ohaeto \& Akujobi, 2013), even though this is contrary to the provisions of the National Policy on Education. Besides, as the official language, English has higher status in Nigeria than any of her indigenous languages. Although the Nigerian language policy stipulates multilingual education, unfavourable conditions such as lack of developed orthography, reading materials and trained teachers of the indigenous languages make it difficult to implement. Many African countries have similar scenarios, by preferring the ex-colonial languages both as their official languages and the language of education.

The extent of language endangerment in Africa is somewhat hidden, perhaps due to the number of languages that are in existence within the continent. For instance, Simons and Lewis (2013), on assessing the linguistic situation in the world report that "at one extreme, more than $75 \%$ of the languages that were in use in 1950 are now extinct or moribund in Australia, Canada, and the United States, but at the other extreme, less than $10 \%$ of languages are extinct or moribund in sub-Saharan Africa" (p. 5). Similarly, Moseley (2010) states that "quite a number of major African languages are vital and are even gaining speakers" (p. 20). However, the number of languages that are "in trouble, dead or dying" in Africa are more than all the languages in Europe put together. Available statistics (Simons \& Lewis, 2013, p. 25) shows that in Europe (Eastern, Northern, Southern and Western), there are a total of 292 languages out of which 49 are in trouble while 56 are dead or dying (that is to say, 105 of their languages are endangered). However, in Africa (Middle, Eastern, Northern, Southern and Western), a total of 209 languages are in trouble while 175 are dead or dying; that gives a total of 384 . Even Nigeria alone has more languages than the whole of Europe put together. Thus, if twenty languages are threatened in Africa, it may not be as prominent as a single language that is threatened in Europe. In Nigeria alone, 74 languages are endangered (30 are in trouble and 44 are dying) (Simons \& Charles, 2018).

Another reason why the extent of language endangerment in Africa is somewhat hidden could be because many of her indigenous languages might not have been documented. Sallabank (2010) is of the opinion that complete information on all of the world's languages is not available because many of 
them have not been recorded or analysed by linguists, have no dictionaries or even written form, and are not officially recognized in the countries in which they are spoken. In Africa for example, many indigenous languages have no orthography. Documenting African languages has also been impeded as linguistic fieldworkers have been unable to make surveys in some parts of the continent due to "continuing warfare and unsafe conditions" (Wurm, 2001, p. 42). Thus, some African languages may even go into extinction without being documented or noticed. Without looking deeper, it might be easy to conclude that African languages are safe. On the contrary, the situation is not all that promising when the larger picture is taken into consideration. If one considers the number of languages in Africa, 10\% is a huge number and their loss affects a great number of the rural people who have relied on them down through the ages for their daily communication and survival in an ever-increasing competitive world.

In Africa, the endangerment and eventual disappearance of entire language families are imminent. According to Moseley (2010), the entire Khoisan phylum language family is presently endangered as most of them are now spoken only by small and marginalized former hunter-gatherer communities. Speakers of languages belonging to this family are shifting to the Maa language along with the pastoral way of life. Besides, the Kordofanian languages in Sudan and the Kuliak languages in Uganda are equally endangered (p. 24-25).

In Africa, cases of tribal and inter-tribal wars, natural disasters and effects of global warming (including drought, storm surge and encroaching desertification) and political and religious tensions are daily increasing the pace of displacement and migration, thus making language shift, endangerment and loss an ever-increasing reality. Going by the criteria for language vitality index listed in UNESCO (2003), many African languages can no longer be classified as safe or fully alive. There is therefore, the need to consider how the African languages are faring, taking into consideration the global context of civilisation and the prevailing language loss in the world. Perhaps if the true situation is made more visible, the respective governments of the African countries could take more drastic action to save these languages.

\section{Language endangerment: From global to African perspective}

Language endangerment and extinction has become a global phenomenon, affecting every continent. Both the developed and developing nations are facing this reality, and it is also happening at a rapid pace. Krauss (1992) had estimated that $90 \%$ of the world's languages would be severely endangered by 2100 . Some regions are more affected than others. The available statistics (Simons \& Lewis, 2013, p. 17) shows that only $68 \%$ of the languages in the world are safe and $32 \%$ (that is, about 2,384) living languages 
"are in some stage of loss or shift"; 5\% of the languages in use in 1950 are now completely extinct and 19\% of the world's living languages are no longer being learned by children. Further classification by the authors shows that out of the 7,480 identified languages of the world a total of 1,024 (13.7\%) are threatened, $456(6.1 \%)$ are shifting, $286(3.8 \%)$ are moribund, $431(5.8 \%)$ are nearly extinct, $187(2.5 \%)$ are dormant and 377 (5.0\%) are extinct (p. 24). With the high rate of language endangerment and their eventual loss in the foreseeable future looming, there is a need for a quick action.

Language endangerment is not a new event in human history; it has happened down through the ages. However, there seems to be a different dynamic and trend in the modern world. Comparing the present with the past, Hale (1992) explains that language loss in the past had been "marked by grammatical merger in situations of multilingualism, in geographically confined areas and among quite small communities". However, the present trend in the modern period "is of different dimensions and implications: it is part of a process of loss of cultural and intellectual diversity in which politically dominant languages and cultures simply overwhelm indigenous local languages and cultures" (p. 1). This implies that there could be deliberate intentions to destroy some "weaker" or minority languages by the dominant cultures and this is scary as the world is becoming more and more globalised. United Nations (2008) points out that although language loss has happened in the past, what is happening today is "an unprecedented threat to linguistic diversity" which gravely affects the indigenous people (Art. 31).

English language has been a threat to many indigenous languages in African countries where it was implanted through colonialism and imperialism. Wamalwa and Oluoch (2013) rightly observes that though many scholars would agree that English as a lingua franca is a necessity in the $21 \mathrm{st}$ century largely due to the electronic age and mass media, they hardly consider its negative impacts on most of the other world's languages. English is not alone in this linguistic threat. Other world languages such as Russian, French and Hans Chinese pose similar threats to the survival of many local languages around the world (Krauss, 1992; Bruhn, 2008; Wurm, 2001).

In terms of language loss by regions, Simons and Lewis (2013) rank Australia and New Zealand first, with 317 dead and dying languages, followed by South America (204), Northern America (163), South-Eastern Asia (131), and Melanesia (81). On the African situation, the authors state that SubSaharan Africa is "the part of the world least impacted by language endangerment" and that "the three regions of Western, Eastern and Middle Africa all have more than $80 \%$ of their languages in the vital category" (p. 11). In spite of the above, United Nations (2012) warned that although Africa is considered the most linguistically diverse continent in the world, many of her languages are the most endangered (Art. 34). This assertion may be based on 
many competing factors that retard language vitality or development within the continent. These factors include high rate of underdevelopment, illiteracy and poverty, lopsided language policies that favour the use of ex-colonial languages as official languages and languages of education, poor language planning, lack of investment in indigenous language development, poor language attitude and language shift by speakers of minority languages, all of which put the survival of the indigenous languages at stake. According to Moseley (2010), a combination of some external and internal forces, including poverty, marginalisation and a community's negative attitude towards its own language contribute to limiting the intergenerational transmission of linguistic and cultural traditions. These forces, continued the author, influence parents to prefer their children speaking a different language other than their own "to overcome discrimination, attain equality of opportunity and derive economic benefits for themselves and their children" (p. 21).

The family is the centre of the indigenous language use and their intergenerational transmission since children will most likely acquire the languages they are exposed to from home and encouraged to learn. However, if they are made to shift to another language or exposed to education delivered in a language other than the ones spoken at their homes, especially their mother tongue, language shift is bound to occur. The more the young people shift to the languages of education, the more the local languages are abandoned and therefore, threatened. Wa Mberia (2014) states that the predominant use of "European languages in the formal domains in Africa denies the indigenous languages the opportunity to be modernized for today's technological world" thereby making them less and less relevant in the fast growing modern world (p. 136). Simons and Charles (2018) add that the fewer the domains of life a language is being used, the more it will lose its structural complexity; this may in turn "affect the perceptions of users regarding the suitability of the language for use in a broader set of functions" and "can lead to a downward spiral which eventually results in the complete loss of the language" (p. 1).

Close to 30 years ago, Kraus (1992) made a stark revelation about the crisis languages are facing across the world. The author asserted that:

The Eyak language of Alaska now has two aged speakers; Mandan has 6, Osage 5, Abenaki-Penobscot 20, and Iowa has 5 fluent speakers. According to counts in 1977, already 13 years ago, Coeur d'Alene had fewer than 20, Tuscarora fewer than 30, Menomini fewer than 50, Yokuts fewer than 10. On and on this sad litany goes, and by no means only for Native North America. Sirenikski has two speakers, Ainu is perhaps extinct. Ubykh, the Northwest Caucasian language with the most consonants, 80-some, is nearly extinct (p. 4). 
The above revelation by Klaus might sound like a fairy tale, yet it was the reality 27 years ago. More dismal is the fact that perhaps most of the abovedescribed languages might have gone into extinction. The question then is, will African linguistic situation ever come close to the reality painted above? It may sound incredible and appear impossible, but the reality is that if nothing is done to equip her numerous indigenous languages, many of them will come to the same fate as the ones mentioned above. Indeed, many African languages are on the path to extinction. The high vulnerability of African languages is obvious if one places them at par with UNESCO (2003)'s criteria for evaluating language vitality.

\section{Degrees and Causes of language Endangerment in Africa}

UNESCO (2003) identifies six major evaluative factors of language vitality. On top of the list is the level of intergenerational transmission, that is, the language is passed from the older speakers to the younger ones. This is followed by the absolute number of speakers, proportion of speakers within the total population, trends in existing language domains, response to new domains and media and materials for language education and literacy. It stresses that these factors are interwoven and therefore, none of them should be used alone because a language may rank high using one criterion but may actually "deserve immediate and urgent attention due to other factors" (p. 7). Supporting the postulation of Fishman (1991) UNESCO (2003) equally observes that "the most commonly used factor in evaluating the vitality of a language is whether or not it is being transmitted from one generation to the next". It further gives five degrees of endangerment based on the criteria of intergenerational transmission of languages (graded from 5 - 0) (p. 7-8).

If the vitality of many African languages is measured with the abovementioned evaluative factors, many of them will rate very low. Language loss is taking place in all regions of Africa. In the Atlas of the World's languages in Danger, Moseley (2010) presents a clearer picture of the state of the African languages. As at 2010, North Africa has a total of 8 extinct Languages and 10 critically endangered ones. Distribution by country shows that among the 8 extinct languages, 3 of them were in Morocco, 2 in Sudan, and one each in Tunisia, Egypt and Chad. Of the critically endangered, 3 are in Algeria, 2 in Mauritania, 2 in Morocco and one each in Tunisia, Libya and Chad respectively. In West Africa, 14 languages have gone into extinction: 4 in Cameroon, 2 each in Chad, Nigeria, Cote d'Ivoire and Sierra Leone, then one each in Togo and Guinea (p. 188-195). However, 8 Nigerian and 4 Cameroonian languages represented in the $2^{\text {nd }}$ edition of the Atlas of the World Languages in Danger of Disappearing (Wurm, 2001, p. 67) were not represented in this third edition of the Atlas (Moseley, 2010). This means that Nigeria and Cameroon may have more extinct languages than the other 
countries. West Africa also has a total of 43 critically endangered languages out of which 13 are in Nigeria, 15 in Cameroon, 7 in Chad, 4 in Guinea, one each in Benin, Senegal, Sierra Leone and Ghana.

Coming to the Southern Africa, a total of 13 extinct languages were identified: 7 in South Africa, 3 in Angola, 2 in Tanzania and one in Botswana. The critically endangered ones are 8, out of which 3 are in South Africa, 3 in Botswana and 2 in Tanzania. Then in East Africa, there are a total of 20 extinct languages. Out of these, Sudan and Kenya have 6 each, Ethiopia and Uganda have 3 each while Chad and Central African Republic have one each. Besides, there are 33 critically endangered languages in East Africa out of which 15 are in Sudan alone, 5 in Chad, 4 in Ethiopia, 2 each in Somalia, Central African Republic and Kenya, and one each in the Democratic Republic of Congo and Tanzania.

Worthy of note is the fact that: two languages (Duli, Nagumi - in Cameroon) and Homa (in Sudan) that were classified as seriously endangered in the $2^{\text {nd }}$ edition of the Atlas (Wurm, 2001, p. 66-67) were classified as extinct in the $3^{\text {rd }}$ edition (Moseley, 2010, p. 188-195). Besides, 9 languages: Odut (Nigeria), Birgid and Gule (Sudan), Sogoo (Kenya), Li-Ngbee (Democratic Republic of Congo), Nyang'i (Uganda), Kwadi and Kwisi (Angola) and Deti (Botswana) classified as moribund, that is, left with elderly speakers in year 2001 ( $2^{\text {nd }}$ edition) are equally represented as having gone into extinction by 2010 ( $3^{\text {rd }}$ edition). It is therefore obvious, from the available statistics that language shifts, endangerment and extinction exist in all parts of Africa. It is also obvious that African languages are indeed dying at a gradual but steady pace. In West Africa, Nigeria and Cameroon are leading in language extinction and endangerment. This might be due to the high number of languages present in the two countries. It is possible that the more languages a country has, the more difficult managing or sustaining them might be.

Linguistic vulnerability and problems in Africa are twofold: the dominant African languages are replacing the minor ones while the excolonial languages threaten both the major and minor languages. The linguistic situation is African is turning into a game of the survival of the fittest. Wurm (2001) observes that the endangerment of African languages, especially small ones, results from the pressure exerted by the larger ones. Simons and Lewis (2013) add that "in this age of globalization, even official national languages are beginning to feel threatened by the languages of globalization" (p. 1). In East Africa for example, Swahili threatens more than 130 Tanzanian languages, while Setswana remains a threat to about 30 languages spoken in Botswana (Moseley, 2010, p. 22). However, Setswana is equally under threat because even though it is designated as the country's national language, it is assigned limited roles compared to English language (Nkosana, 2009). Furthermore, wa Mberia, (2014) asserts that "the only 
members of the East African community without serious issues of language endangerment are Rwanda and Burundi where Kinyarwanda and Kirundi, respectively, are the only languages spoken" (p. 137).

In Nigeria, many indigenous languages are also under threat both by English which is the official language and other major languages. Most of the Nigerian endangered languages are concentrated in the Northern part of the country. Hausa for example, is a de facto provincial language in the northern region of Nigeria, spoken by over 48 million people in the country, out of which L1 users are up to 33 million and the L2 users are up to 15 million (Simons \& Charles, 2018). As a dominant language, Hausa remains a threat to many indigenous languages in the region. It is a threat to six indigenous languages spoken in Niger State (Adewale \& Oshodi, 2013), to the minority languages in Kano State, Kebbi State, Jigawa State and Sokoto State (Agantiem, 2017) and to the Bole language spoken in Gombe and Yobe States respectiely (Haruna, 2017). In Cross River State, (Southern part of Nigeria), Efik, which is considered the lingua franca in Calabar metropolis threatens the survival of the minority languages, most especially Efut and Qua (Agantiem, 2017). At the border between Nigeria and Cameroon known as the Mambila region, language endangerment has occurred massively due to language shift to the neighbouring ones and also reduced population of the minority languages speakers (Connell, 1997).

Whenever speakers of one language shift to another one for whatever reasons, the former language tends to be threatened as it invariably loses speakers. Causes of language shift and endangerment in Africa are numerous and almost inexhaustible. One of the causes has been identified as change in religious affiliation (Moseley, 2010) whereby those who embrace a religion often "abandon their ethnic languages" in order to speak the language associated with their religion (p. 22). In Côte d'Ivoire for example, the Jeri people "adopted two different languages as their new mother tongues according to their religious affiliation: Sienare by the non-Muslims, and Manding by the Muslim Jeri" (Kastenholz, 1998) cited in Moseley (2010, p. 22). Also in Nigeria, Hausa (and Arabic) are associated with Islam since a greater number of the northerners are Muslims. However, the Nigerian situation is a bit dissimilar. The country's politics is also dominated by the northerners; thus, the language has not only religious but political and socioeconomic undertone, especially among the minority groups in the north. Hence, the minority tribes tend to give up their languages not necessarily because of religious affiliation but for political participation, education and wider communication. Meanwhile, Northeast is also a region that has been more destabilised due to the onslaughts of Boko Haram and the resultant displacement of many minority groups. Displacement can negatively affect minority language vitality. 
Political ideology and unfavourable language policy are other factors that leave the African languages vulnerable. The governments of some African countries favour the ex-colonial languages, especially English and French, and are against the use of any African language of their countries for official purposes (Wurm, 2001). There seems to be a political ideology among many African governments that make them consider multilingualism as a threat or burden and therefore, consciously try to repress it. This is in line with one of the assertions made by the United Nations (2008) that even though the current trend in language loss is attributed to globalization and migration, "it is also a result of systemic and deliberate efforts to destroy languages using racist and discriminatory policies and laws" (Art. 31). It is the governments that make those laws and policies.

Moreover, while Africa's past-colonial experience contributed to and is often blamed for language endangerment in many African countries, the past and present post-independent governments of the African nations have a greater share of the blame for the near extinction of many indigenous languages. Most of their policies have tended toward anti-linguistic pluralism. For example, Bulcha (1997) cited in Anchimbe (2006) observed that the Ethiopian king, Halle Selassie not only prohibited the teaching of indigenous languages - because they hindered his "nation building" projects but also destroyed all literature in the Oromo language. In Kenya, the government continued with the colonial language policy after independence by making conscious effort to subvert some local languages, including Bogom (wa Mberia, 2014). This policy led to the endangerment of the Bongom language. Presently, Bongom (Bong'om) is classified as a seriously endangered language in the 3rd edition of the Atlas of the World's Languages in Danger. The situation in North Africa is not in any way different. According to Moseley (2010), language matters are cleverly avoided by the governments in that region, to the extent that "no North African state has ever organized sociolinguistic studies or included the geographical distribution of languages in a population census, and attempts to gather language statistics are often discouraged" (p. 26). To be precise, in Sudan, the author asserts that the national policy known as "Sudanization" is considered a calculated strategy meant to reduce ethnic and linguistic pluralism in favour of linguistic unification.

Until recently, Igbo, Yoruba and Hausa had been classified in Nigeria as the "major languages" and even given official status as "national languages" out of over 500 languages that exist in the country. School children were mandated to study one out of the three. However, the country's language policy has been upgraded to accommodate other minority languages in education by using the term "any Nigerian language that has curriculum" (Federal Republic of Nigeria, 2014, p. 20). While the language policy is 
intended to make school children multilingual, given the linguistic heterogeneity of the country, the policy is still far from being successfully implemented. Its failure is largely because the government is yet to put in place the necessary mechanisms that would make it implementable, including orthography development, provision of educational materials and training of teachers of the languages. Such loopholes have marred the possibility of achieving a tongue-based multilingual education which could have hastened the development and survival of her many indigenous languages.

In Cameroon, Anchimbe (2006) states that shortly after gaining political independence, the indigenous languages such as Duala, Basaa, Ewondo, Bulu, Fulfulde and Fe'efe'e were taught at the Federal Universities between 1970 and 1977. However, this move was soon abandoned due to frictions that arose between speakers/users of taught and untaught languages, with the latter considering the former as being privileged by the government. The government took a rash decision by not only halting indigenous language education but "became ruthless in enforcing the decision" by suppressing all projects in that direction (p. 99). That was quite unfortunate. It was a good and noble initiative but badly handled by the government. While it might be easy to lay the blame for such failure on the indigenous people, the truth is also that in multilingual settings, language conflict is inevitable, especially when one language is raised in higher rank over the rest. The government ought to have envisaged such conflict and be prepared for it. Rather than suppressing the project, it should have intensified effort to at least raise the status of more local languages.

Another disturbing issue raised in Anchimbe (2006) is the fact that the Cameroonian government did not seem to even support the effort of the private sector who tried to promote the country's indigenous languages. According to the author, some non-governmental bodies such as SIL and NACALCO worked for the use of more local languages at the primary school level. However, the numerous languages that these bodies were able to standardise were not officially welcomed in education and were therefore not included in the school curriculum: they had no state-recognised role and those who studied them had neither qualifying nor end-of-course examinations planned for them. This kind of lackadaisical attitude towards the indigenous languages is enough to demotivate students from learning them, especially for functional literacy. With up to 166 languages already standardized, the author asserts that if they are to be adopted in the educational curricular, less technical works would be required. This assertion implies not only that there is a continued neglect of these languages in education but also that standardization is not enough to make a language functional unless the government backs it up. Unfortunately, the government seems reluctant to do so. 
Other issues in Africa that have heightened language endangerment include increased movement of people leading to more cosmopolitan settings especially in the urban areas, migration - both by choice and by force, and violence which leads to displacement and sometimes mere extermination of the local populations. African migrants and displaced persons often have to acquire new modes of communication. In Southern Sudan for example, many years of civil war has meant the death of up to 1.5 million people, 4 million internally displaced persons (IDPs) and 500,000 refugees (Moseley, 2010, p. 30). In Nigeria, the onslaughts of Boko Haram and Fulani herdsmen have equally led to so many deaths, so much displacement of families, and the abandonment of ancestral lands for lack of security. Ugwu and Ogunremi (2019) note that due to the incessant attacks of Boko Haram and armed Fulani herdsmen in Nigeria, "the establishment of Internally Displaced Persons' camps (IDPs) has become a norm, rather than an exception" (p. 63). In East Africa, notably Mozambique, Malawi and Zimbabwe, recent unprecedented storm surges have killed thousands of the local population and displaced many. In Cameroon, Libya, Central African Republic, Burundi, Sudan and South Sudan, political tension and different forms of violence continue to ravage and displace the citizens.

The displacement and death of many local people, most especially within the same geographic area means that language deaths are inevitable. The displaced persons, most likely, have to live in a new environment where they sometimes have to mix up with people with different linguistic and cultural orientations. In that case, language contacts are inevitable and this could lead to the loss of or threat to the survival of the displaced persons' languages. Children who have to go to school in the camps would have to study in any available language, most likely, that of the host community. If the "new arrivals" outnumber the host community, the language of the latter might as well be threatened as the former becomes more prominent.

Envisaged economic advantage as well as ideological shift is another factor in language shift within the African continent. Moseley (2010) enumerates the different areas where language shifts have occurred in different parts of Africa including the hunter-gatherer communities in Gabon such as the Babongo who have shifted to the languages of their neighbours and the fishing communities in Ethiopia, South Africa and Kenya who live in the different islands around the African Rift Valley (p. 24). Accordingly, their languages are all threatened and mainly because of the threat to the species of fish they had relied on for sustenance. The author believes that poverty not only threatens the languages spoken by the minority groups but also could be the prime reason why they abandon their own languages (p. 25). The rural poor minority groups would often look for a way out of their poverty, including by shifting to a language that seem to offer better economic 
advantage. Thus, language shift becomes a liberating tool to wellness and economic gains. In Nigeria for example, English language is considered "the badge of the educated" (Fafunwa, Macaulay \& Sokoya, 1989, p. 137) and education of course gives one economic advantage from every indication. Given the enviable position assigned to English language, proficiency in it is equally regarded as the road to upward mobility (Ugwu and Ogunremi, 2019). The more the citizens, especially the young people, make English their preferred mode of communication, the more the indigenous languages lose speakers and become more vulnerable.

The Delegates to the Asmara Conference pointed out that "the vitality and equality of African languages must be recognized as a basis for the future empowerment of African peoples" (The Asmara Declaration, 2000, p. 1). Unfortunately, "African languages are currently marginalized or totally ignored in the activities of national, regional, sub-regional and continental economic programmes, including the New Economic Partnership for Africa's Development (NEPAD), the African Renaissance and the Native Club of South Africa" (Ndhlovu, 2008, p.144). While Chinese and other European languages are taught in many African universities, more African languages are yet to be taught in African universities. There is a great need to save the African languages.

\section{The need for Action}

If indeed Africa "acknowledges its ethno-linguistic pluralism and accepts this as a normal way of life and as a rich resource for development and progress" (Chimhundu, 1997, p. 44), then her languages must not be left to continue going into extinction. Decisive actions are needed not only for the sake of saving the languages for the languages' own sake but also because of the implications their loss have for their speakers and the continent at large. Language problems in Africa are complex, and so, finding the right solutions cannot be a one-way traffic, neither will it be easy. However, one solution could serve as a stepping stone to the other and therefore facilitate the process of reversing the trend of language endangerment.

One of the surest ways of ensuring language vitality is by using it in and for education. Education that favours one language over the others has been identified as a significant contributor to language endangerment. This is especially true in multilingual African nations where a second language is often the preferred medium of instruction. Ball (2010) stressed that in most countries, the vast majority of formal school systems either require children to acquire a national or international language at school entry or soon after and that according to current research, this trend threatens the preservation of the world's linguistic and cultural diversity. This is also irrespective of the fact that the indigenous languages, notable, learners' mother tongue (MT) are 
recognised worldwide as the best medium of education of the indigenous children. Education in language other than that spoken by children at home has been associated with reduced access and achievement (Pinnock \& Vijayakumar, 2009). The Association for the Development of Education in Africa (ADEA, 2006) observed that "in most Sub-Saharan African countries where the official language is the preferred medium of instruction, "the low quality of teaching is mainly related to the fact that teachers are obliged to use a language which - in fact - is unfamiliar to both, teachers and learners" (p. 16).

While the use of the indigenous languages in education has its own challenges, especially where many languages exist, promoting additive, rather than subtractive bilingualism seems to offer some possible solutions. This means that instead of rendering education in the national or official language alone, the learners' mother tongue are used alongside the former, so that learners acquire education in both and use them interchangeably for functional literacy. This way, the official language is not learnt at the risk of losing the MT, and learners are also not put at any disadvantage by losing their MT through education. Learning the official language is important for wider communication and to enable them function in the globalised world. However, delivering education in both the mother tongue and the official language will remove the linguistic barriers that many rural children could face in their quest to access education. According to ADEA (2006), language is important for the quality teaching and efficient learning in all other subjects but unfortunately, is a major barrier to functional literacy development in Sub-Saharan Africa. The group re-echoed the saying of Ekkehard Wolff that "language is not everything in education, but without language, everything is nothing in education" (p. 9). Learners need proficiency in the language of education in order to fit into the school system and make the most out of it. Literacy is a key to empowerment and survival in the world. In Africa, where "seven out of ten children are likely to become semi-literate adults" and "over 150 million youth and adults have either never become literate or have lost their literacy skills" (ADEA, 2009, p. 9), revitalisation of the indigenous languages for functional literary is very important.

Moreover, the indigenous languages are essential for political participation and responsible citizenship. Delegates to the Harare Intergovernmental Conference on Language Policy in Africa conceptualised this aptly by undertaking "to enhance the participation of all our national communities in the public life of our countries by guaranteeing them a hearing in whatever language they use to express their thoughts and feelings concerning public matters" (Chimhundu, 1997, p. 46). If the indigenous languages are left to continue going into extinction, their speakers who are forced to shift to other languages are invariably denied of the right to self- 
expression and full participation in the national life. This also robs them of their identity.

There is also the need to develop the languages in order to retain the rich cultural heritage inherent in them. Every language is unique in itself but most especially to its speakers. Languages are vehicles of cultures, a people's collective memory and their values (UNESCO, 2011). Thus, the disappearance of any language is an irreparable loss for the heritage of all humankind (Wurm, 2001, p. 90). According to Ndhlovu (2008), a marginalised language dies with the people's accumulated wisdoms "wisdoms about politics, about philosophy, about ideology, about living on the planet earth and successfully doing so" (p. 143). The revitalisation of African languages would enable the citizens to gains access to the wisdom and culture that these languages carry and have preserved for ages. It also enables the people of the continent to retain their multilingual identity. Multilingualism, that is, the ability to communicate in several languages is itself a rich source of human enhancement. It benefits the individuals, organizations, and the society at large. Multilingualism enhances creativity, breaks cultural stereotypes, encourages thinking "outside the box", and can help develop innovative products and services (Jones, 2013).

If the continent is to continue reaping the fruits of her linguistic endowments, there is an urgent need to enhance language development. This can be achieved through raising the status of the local languages to be at par with the ex-colonial languages that so far are the dominant official languages in most African countries. To this end, putting in place language policies that favour multilingualism and using more indigenous languages in all levels of education should be a priority. The governments also need to take advantage of the current technological growth to empower the indigenous languages by making them prominent in the cyberspace and mass media. Through the mass media, the citizens could be educated on the need to preserve their languages by having positive attitude towards them. However, since language attitude is linked to socio-economic factors, the empowerment of the local people is crucial to their retaining their respective indigenous languages. So far they are left behind in the socio-economic ladder, they will continue to give up their languages and embrace the ones that appear to offer them access to an improved standard of living.

Moreover, the leaders of the African nations need to change their own negative attitude towards multilingualism and language development before it can influence the citizens. Since the governments wield both political and economic powers, constructive language planning and policy must go hand in hand with adequate budgeting for language development. Therefore, they need to make provisions for indigenous language development. Besides, the governments need to collaborate with the private sector, non-governmental 
organisations and the international community towards indigenous language development in Africa.

\section{Conclusion}

The potential benefits of languages are numerous. However, the present world is becoming very harsh to language survival and growth. Thus, language endangerment is a stark reality in the modern world, Africa inclusive. As the world becomes more and more globalised, language contact is unavoidable. However, in the world arena, only very few languages are making it to the top and those lucky few threaten the survival of the vast many that are now in a perilous state. In Africa, due to the many languages that are in existence, it appears, on the periphery, as though her languages are safe. However, the reality is that the continent is faced with a continued threat to many of her local languages. This is happening at a steady pace and all parts of the continent are affected. Many African languages have actually gone into extinction, many are threatened at varying degrees and none of them is completely safe. There are many factors, both internal and external which constitute obstacles to the continued survival of these languages, including political ideology evident in language policies that not only discourages multilingualism but favours the use of ex-colonial languages, lack of investment in language development and denial of the indigenous languages public space in education, the media and in politics. These are in addition to language shifts by speakers of the minority languages resulting from language attitude, migration, forced displacement and the need to learn other languages for socio-economic advantages. In the light of the numerous benefits of the indigenous languages to their speakers and the society, the governments of African nations need to take a drastic step to reduce the pace of language endangerment in the continent. They should find ways to revive the languages that are critically endangered, invest in language development so that they can be used for functional literacy and promote them in education and other public sectors.

\section{References:}

1. Adewale, R. K. and Oshodi, B. (2013). Language endangerment in Nigeria: Focus on small ethnolinguistic communities in Niger state. Dialectologia, 11, 17-45

2. Agantiem, A. A. (2017). Language (in) equality, language endangerment and the threats to Nigerian languages. Journal of Literature, Languages and Linguistics, 37, 21-28. www.iiste.org

3. Anchimbe, E. A. (2006). Functional Seclusion and the Future of Indigenous Languages in Africa: The Case of Cameroon. In Selected Proceedings of the 35th Annual Conference on African linguistics, ed. 
John Mugane et al., 94-103. Somerville, MA: Cascadilla Proceedings Project. www.lingref.com, document \#1300.

4. Association for the Development of Education in Africa (ADEA). (2006). Proceedings of the Regional Conference and Expert Meeting on Bilingual Education and the Use of Local Languages. Final Report.

5. Association for the Development of Education in Africa (ADEA). (2009). More and Better Education What Makes Effective Learning in African Literacy Programs?

6. Ayenbi, O. F. (2014). Language regression in Nigeria. Éducation et Sociétés Plurilingues, 36, 51-64. URL: http://esp.revues.org/136

7. Ball, J. (2010). Enhancing Learning of Children from Diverse Language Backgrounds: Mothertongue-Based Bilingual or Multilingual Education in Early Childhood and Early Primary School Years. Retrieved from http://unesdoc.unesco.org/images/0021/002122/212270e.pdf

8. Bruhn, D. (2008). Minority Language Policy in China, with Observations on the She Ethnic Group. Linguistics $250 E$ Endangered Languages. Retrieved from http://linguistics.berkeley.edu/ dwbruhn/dwbruhn_250E-paper.pdf

9. Chimhundu, H. (ed.) (1997). Language Policies in Africa: Intergovernmental Conference on Language Policies in Africa, Harare, Zimbabwe. Final Report (Revised). Harare: UNESCO. Retrieved from http://unesdoc.unesco.org/images/0014/001457/145746e.pdf

10. Connel, B. (1999). Moribund Languages of the Nigeria-Cameroon Borderland. Symposium on Language Endangerment in Africa.

11. Ezenwa-Ohaeto, N. and Akujobi, O. S. (2013). English as a second language in contemporary Nigerian society, a reality or farce? Awka Journal of English Language and Literary Studies, 4(1), 45-60.

12. Fafunwa, B., A., Macauley, J. I. and Sokoya J. A. F. (Eds.). (1989). Education in Mother Tongue: The Ife Primary Education Project (1970-1978). Ibadan: University Press. Retrieved from https://eric.ed.gov/?id=ED350120

13. Federal Republic of Nigeria. (2014). National Policy on Education. ( $5^{\text {th }} \mathrm{Ed}$.).

14. Hale, K. (1992). On endangered languages and the safeguarding of diversity. Languages 68(1), 1-3. Retrieved from http://www.ling.ohio-state.edu/ joseph.1/Ling311/HaleEtAl.pdf

15. Haruna, H. H. (2017). Linguistic diversity and language endangerment: Towards the revitalisation of Bole language in Nigeria. International Journal for Innovative Research In Multidisciplinary Field, 3(10), 108-113. 
16. Jones, M. P. (2013). Endangered languages and linguistic diversity in the European Union. Retrieved from http://www.europarl.europa.eu/RegData/etudes/note/join/2013 /495851/IPOLCULT_NT(2013)495851_EN.pdf

17. Krauss, M. (1992). The world's languages in crises. Languages 68(1), 4-17. Retrieved from http://www.ling.ohiostate.edu/ joseph.1/Ling311/HaleEtAl.pdf

18. Moseley, C. (ed.). (2010). Atlas of the World's Languages in Danger. ( $3^{\text {rd }}$ Ed.). Paris: UNESCO Publishing. Retrieved from www.unesco.org/culture/en/endangeredlanguages

19. Ndhlovu, F. (2008). Language and African development: Theoretical reflections on the place of languages in African studies. Nordic Journal of African Studies 17(2): 137-151.

20. Nkosana, L. B. M. (2009). The linguistic situation in Botswana and Achievement of Millennium Development Goals. The African Symposium: an online Journal of African Educational Research Network, 9(2), 7-19.

21. Pinnock, H. and Vijayakumar, G. (2009). Language and Education: The Missing Link. Retrieved from http://www.unesco.org/education/EFAWG2009/LanguageEducation. pdff

22. Sallabank, J. (2010). Language Endangerment: Problems and Solutions. Retrieved from http://www.gla.ac.uk/media/media_141050_en.pdf

23. Simons, G. F. and Charles, C. D. (eds.). (2018). Ethnologue: Languages of the World. (21 ${ }^{\text {st }}$ Ed.). Dallas, Texas: SIL International. http://www.ethnologue.com

24. Simons, G. F. and Lewis, M. P. (2013). The World's Languages in Crisis: A 20-year Update. Retrieved from http://www01.sil.org/ simonsg/preprint/Wisconsin\%20Symposium.p df

25. The Asmara Declaration on African Languages and Literatures. (2000). Retrieved from https://www0.sun.ac.za/taalsentrum/assets/files/Asmara\%20Declarati on.pdf

26. Ugwu, E. O. and Ogunremi, P. O. (2019). Nigeria and the Sustainable Development Goals: Why the indigenous languages count. European $\begin{array}{lll}\text { Scientific Journal, } & \text { 15(5), }\end{array}$ URL:http://dx.doi.org/10.19044/esj.2019.v15n5p52

27. UNESCO. (2003). Language Vitality and Endangerment. Retrieved from 
http://www.unesco.org/new/fileadmin/MULTIMEDIA/HQ/CLT/pdf/ Language_vitality_and_endangerment_EN.pdfs

28. UNESCO. (2011). UNESCO PROJECT. Atlas of the World's Languages in Danger. ( $3^{\text {rd }}$ Ed.). Retrieved from www.unesco.org/culture/en/endangeredlanguages

29. United Nations. (2008). Report of the International Expert Group Meeting on Indigenous Languages. (Report No. E/C.19/2008/3). Retrieved from https://documentsddsny.un.org/doc/UNDOC/GEN/N08 1213 156/PDF/N0821356.pdf?OpenElement

30. United Nations. (2012). Expert Mechanism on the Rights of Indigenous Peoples. Fifth Session. (Report No. A/HRC/EMRIP/2012/3). Retrieved from http://www.un.org /esa/socdev /unpfii/documents/2016/egm/Expert-mechanism-language.pdf

31. United Nations. (2016). Permanent Forum on Indigenous Issues. Fifteenth Session. (Report No. E/C.19/2016/10). Retrieved from https://documents-ddsny.un.org/doc/UNDOC /GEN/N16/055/48/PDF /N1605548.pdf?OpenElement wa Mberia, K. (2014). Death and survival of African languages in the 21 st century. International Journal of Linguistics and Communication, 2(3), 127-144. URL: http://dx.doi.org/10.15640/ijlc.v2n3a6

32. Wamalwa, E. W. and Oluoch, S. B. J. (2013). Language endangerment and language maintenance: Can endangered indigenous languages of Kenya be electronically preserved? International Journal of Humanities and Social Science, 3(7). 258-266. Retrieved from http://www.ijhssnet.com/journals/Vol_3_No_7_April_2013/28.pdf

33. Wurm, S. A. (Ed.) (2001): Atlas of the World's Languages in Danger of Disappearing, Paris,UNESCO Publishing. ( $2^{\text {nd }} \mathrm{Ed}$.). Retrieved from http://unesdoc.unesco.org/images/0012/001236/123609e.pdf 